\title{
HOMENAGEM PÓSTUMA AO PROFESSOR GUSTAVO ZANINI
}

DIA 03 DE MARÇO DE 1988, ÀS 11 HORAS - SALA DA CONGREGAÇÃO DA FACULDADE DE DIREITO DO LARGO DE SÃO FRANCISCO, DA UNIVERSIDADE DE SĀO PAULO. HOMENAGEM À MEMÓRIA DO PROFESSOR DOUTOR GUSTAVO ZANINI, PROMOVIDA PELO DEPARTAMENTO DE DIREITO INTERNACIONAL, INSTITUTO DE DIREITO INTERNACIONAL E RELAÇŌES INTERNACIONAIS, COM APOIO DA DIRETORIA DA FACULDADE DE DIREITO DA UNIVERSIDADE DE SÃO PAULO.

A Sessão foi aberta e presidida pelo Professor Doutor Dalmo de Abreu Dallari, Diretor da Faculdade de Direito da Universidade de São Paulo, Professor Doutor Vicente Marotta Rangel, Chefe do Departamento de Direito Internacional e Conselheiro Fundador do Instituto de Direito Internacional e Relações Internacionais, Professor Doutor Geraldo de Camargo Vidigal, Chefe do Departamento de Direito Econômico e Financeiro e Professora Georgette Nacarato Nazo, Assistente-Doutora, do Departamento de Direito Internacional e Conselheira Fundadora do Instituto de Direito Internacional e Relações Internacionais, que proferiu a Oração.

\section{PROFESSOR DALMO DE ABREU DALLARI:}

"Nós estamos hoje aqui reunidos para render homenagem à memória do colega eminente, profundamente estimado pelos Professores, alunos e funcionários desta Faculdade e que durante muito tempo, longos anos, que esteve conosco demonstrou ser uma figura humana excepcional. Nosso saudoso e querido colega GUSTAVO ZANINI deixou apenas amigos, nesta Faculdade, porque era um constante fazedor de amigos. Um homem afável, cordial, jamais agrediu quem quer que fosse, mesmo quando discordando de alguma coisa, sempre se manifestou com extraordinária elegância, com o mais absoluto respeito pelos colegas. Foi na verdade um docente. Um docente na expressão mais pura do termo e o docente não só no sentido daquele que transmite conhecimento, mas daquele que transmite um exemplo de vida. Isto, foi para nós, GUSTAVO ZANINI. Como seu colega há muitos anos, ultimamente como Diretor, posso dar o meu testemunho, também, de que o Professor GUSTAVO ZANINI foi um cumpridor dos deveres em todas as oportunidades, em toda extensão, estando sempre presente, nunca se furtando ao desempenho de qualquer incumbência que lhe fosse solicitada. Na verdade, por todas essas razões, GUSTAVO ZANINI é uma presença entre nós, presença que continua, uma presença marcante, 
uma presença que não será esquecida. Por tudo isto, tendo em conta a sua grande contribuição à esta Casa, ao Direito e à convivência humana de maneira geral, foi que por iniciativa do Departamento de Direito Internacional a que pertencia nosso querido colega e com absoluta concordância e solidariedade da Diretoria, se decidiu pela realização desta Homenagem. De certo modo, é uma inovação, porque é tradição desta Faculdade homenagear postumamente, em sessão solene, os antigos Membros da Congregação. O Professor Zanini, grande parte devido à sua modéstia, porque sem dúvida teria méritos para estar na Congregação, não chegou à culminância da carreira no ponto de vista formal, entretanto, pelo seu valor humano, pelo seu valor intelectual, nós julgamos que era um dever moral a realização desta sessão solene em sua homenagem. Então, para que isto se dê, eu tenho a honra de passar a palavra em primeiro lugar ao Eminente Professor Doutor Vicente Marotta Rangel que é Chefe do Departamento de Direito Internacional, que, além disso, sendo um dos mais antigos professores desta Faculdade, já tendo sido inclusive seu Eminente Diretor, conheceu muito de perto a figura de GUSTAVO ZANINI. Tenho a honra de passar a palavra ao Professor Marotta Rangel."

\section{PROFESSOR DOUTOR VICENTE MAROTTA RANGEL:}

"Muito obrigado. Excelentíssimo Senhor Diretor, Meus Eminentes Colegas, Ilustríssima Família do Professor Zanini, Senhores Alunos, Minhas Senhoras e Meus Senhores. Em verdade, o Professor Dalmo de Abreu Dallari, numa síntese expressiva, disse quem foi GUSTAVO ZANINI em razão da homenagem. Também falará em nome do Departamento, numa peça principal com incumbência de externar o sentimento de todos nós, a Professora Georgette Nazo, que falará nesta oportunidade. Dispensável seria acrescentar algo mais; todavia, apenas um aspecto me vem à mente suscitar: é que, se existe na visão do Professor Universitário certos traços que chamam mais a atenção, há um que via de regra não é suficientemente focalizado e nesse ponto eu me permito reivindicar uma qualidade que acabei tendo, por força das circunstâncias, mas que não poderia deixar de mencionar. Assim, ao longo de uma vida dedicada à Universidade, eu pudesse trazer um traço específico de contribuição, eu diria que tenho no meu curriculum, a ser talvez incluído no futuro, dizer que tive a iniciativa de encaminhar GUSTAVO ZANINI à vida universitária. Este é um traço que via de regra é o esquecível e quando se pensa na vida universitária, no professor produtivo, vêm à mente apenas dados quantitativos e perecíveis. Há uma série de funções que o professor universitário exerce e talvez uma das menos focalizadas, mas altamente relevante, é a de pressentir aquele que possa dedicar-se à vida universitária e como que a continuar o trabalho fecundo que o mestre deve desenvolver. No caso de GUSTAVO ZANINI, me pennito acrescentar um ponto: ele não era por certo, pelo menos, talvez o fosse, o primeiro aluno da classe, talvez o fosse, talvez não fosse. Não era talvez aquele que no brilho dos debates, talvez fosse, talvez não fosse, aquele que talvez mais se distinguisse. 
O que é certo, porém, é que dentre todos os eventuais postulantes a uma carreira universitária, GUSTAVO ZANINI tinha um amor entranhado ao ensino, a que se dedicava com desvelo e emoção. Eu, muitas vezes, deveria ocupar a regência da disciplina. Estava programado que o faria em determinada data, mas GUSTAVO ZANINI estava presente na Sala da Congregação, no Departamento, como que a desejar continuar a dar aulas e eu então, às vezes, adiava a assumir a cátedra ou a regência do ensino, porque via o grande anseio de ZANINI em transmitir seus conhecimentos e conviver com seus queridos alunos. A Faculdade foi um prolongamento do lar e GUSTAVO ZANINI viveu, apesar de nos últimos tempos sobressaltado pela doença incidiosa, a prestar uma colaboração sempre profícua e fecunda. Muito obrigado Senhor Presidente."

\section{PROFESSOR DALMO DE ABREU DALLARI:}

"Em seguida tenho a honra de convidar a Ilustre Professora Georgette Nacarato Nazo que é professora integrante do Departamento de Direito Internacional, para proferir a oração em homenagem ao nosso querido e saudoso colega."

\section{PROFESSORA DOUTORA GEORGETTE NACARATO NAZO:}

"Senhor Diretor da Faculdade de Direito Professor Dalmo de Abreu Dallari, Professor Marotta Rangel, nosso Chefe do Departamento de Direito Internacional, Prezados Professores, Professor Goffredo da Silva Telles Júnior que muito nos honra com a sua presença, Professor Geraldo Vidigal, Professor Strenger, demais colegas daqui da Faculdade de Direito, Ex-Alunos do Professor ZANINI, Senhoras, minhas queridas amigas Daisy Flora e Silvinha, aqui representando a familia do Professor GUSTAVO ZANINI.

\section{GUSTAVO ZANINI: um exemplo de docente}

Constituir-se-ía um lugar comum dizer-se da falta que GUSTAVO ZANINI fará a todos nós.

Todavia, para quem não é agnóstico e aceita a viabilidade de uma vida extramatéria, certamente encontrará o conforto necessário em saber que GUSTAVO ZANINI adentrou o mundo da verdadeira Justiça.

O homem, o metódico estudioso do Direito e o professor que cumpriu suas tarefas com amor e dedicação, pontilharam sua trajetória neste mundo finito, de infinitas atitudes meritórias.

Nascido em São Paulo, Capital, aos 12 de agosto de 1927, filho de Sereno Zanini e Inês Baú Zanini, fez seus estudos secundários na Capital e colou grau 
234

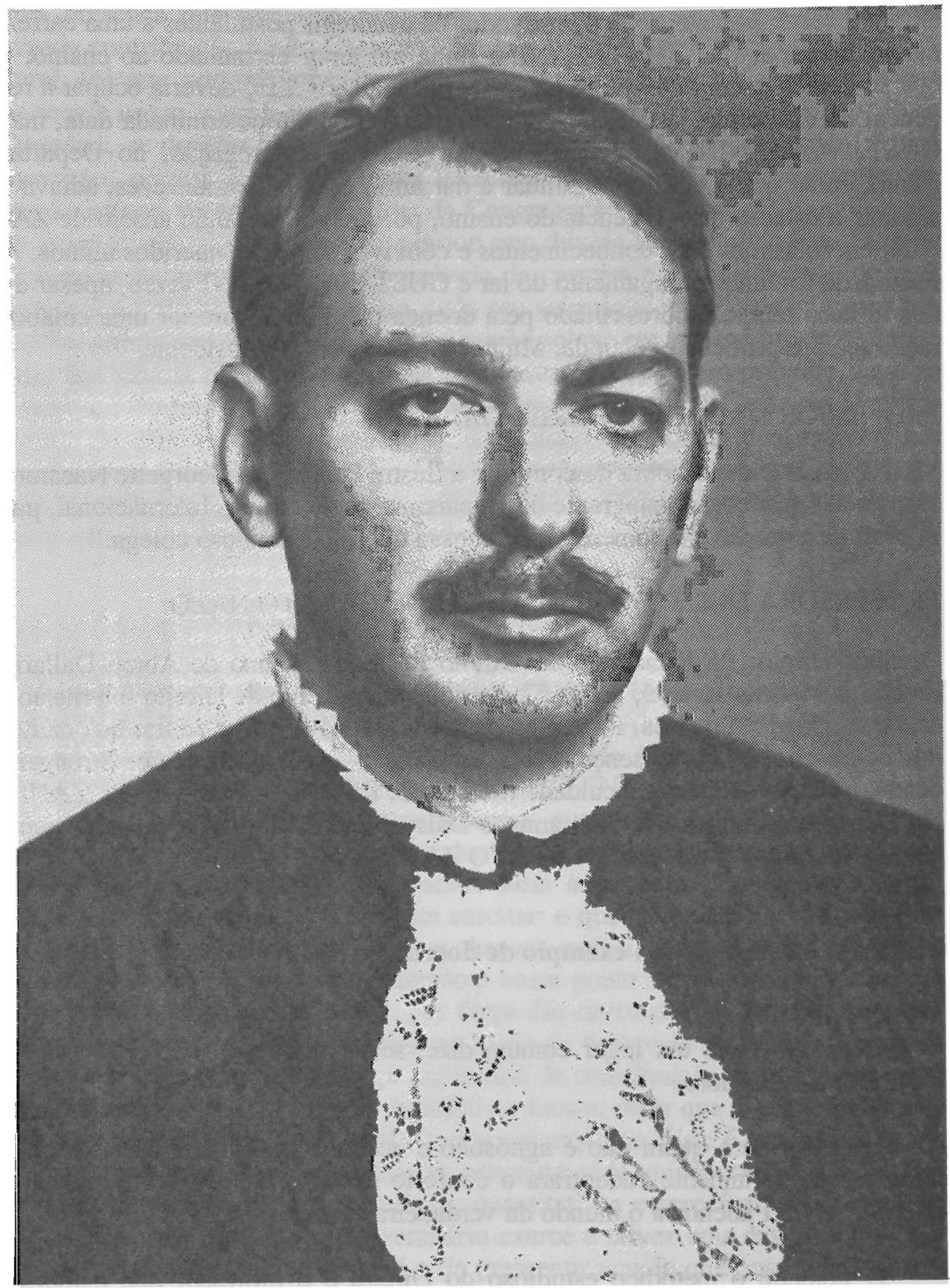


como bacharel em Direito nesta tradicional Faculdade de Direito, aos 25 de março de 1960.

Já diplomado em diversas línguas estrangeiras: inglês, francês, espanhol e italiano, o jovem GUSTAVO iniciou sua peregrinação de estudos no campo do Direito Internacional na Universidade de Roma e na de Milão e daí seguiu para - Centro de Pesquisas da Academia de Haia. Algum tempo depois, estuda Direito Comparado na Universidade de Madrid e freqüenta outro curso da Haia, na Seç̧ão Exterior de Bogotá, na Colômbia.

Retornando ao Brasil, fez o curso de doutorado na Faculdade de Direito da Universidade de São Paulo, conquistanto o título de Doutor em Direito em 1972 com a monografia "O REGIME JURÍDICO E A FUNÇĀO ECONÔMICA DOS RIOS INTERNACIONAIS", dedicado à sua mulher Daisy Flora.

Em alentado estudo, trazendo à colação inúmeros exemplos do Direito Comparado, a tese de doutoramento, revelava a profundidade do pesquisador e a seriedade de quem pretendia dominar o tema. Foi uma eficiente contribuição, apoiada em densa bibliografia e em documentos oficiais, onde examina a natureza jurídica dos cursos d'água, o problema da liberdade de navegação e as tendências modernas, não só jurídicas, como econômicas, para o aproveitamento de todos os seus recursos.

Já era, então, professor contratado da Faculdade de Direito de Bragança Paulista, para as disciplinas de Direito Internacional Público e Privado, desde 1970 e da Faculdade de Direito das Faculdades Metropolitanas Unidas, desde 1972, para ambas as disciplinas. E, na Faculdade de Administração e Economia de Osasco (Estado de São Paulo), regia o curso "Relações Internacionais", quando ainda era professor-assistente, no Largo de São Francisco.

Integrado no Departamento de Direito Internacional na Faculdade de Direito da USP, em 1976, ZANINI pleiteia a dedicação exclusiva à docência e pesquisa, desligando-se, então, das demais Faculdades.

Teve, assim, a oportunidade que almejava: lecionar direito internacional nesta Casa, como assistente direto de nosso estimado Mestre Vicente Marotta Rangel.

E, paralelamente, desenvolvia seus estudos e pesquisas, publicando na Revista da Faculdade de Direito "REFLEJOS DEL DERECHO COMUNITÁRIO SOBRE EL DERECHO NACIONAL" e o "TRATADO DE ITAIPU", O primeiro, data de 1970, quando ainda era professor assistente nesta Faculdade; o segundo é de 1974, já doutor em direito, repensando o tema desenvolvido para concurso; o aproveitamento dos recursos do Rio Paraná, fulcro da existência da Binacional Itaipu. 
Outras contribuiçōes científicas foram dadas por ele à Ciência do Direito: diversos verbetes para a Enciclopédia Saraiva de Direito e, em 1977, um trabalho dedicado à fillha Sílvia: "CONTRIBUIÇĀO AO ESTUDO DA EFICÁCIA DAS RESOLUÇŌES DAS ORGANIZAÇŌES INTERNACIONAIS”.

Membro-Fundador do "Instituto de Direito Internacional e Relações Internacionais", integrava o Conselho da entidade, sendo também Conselheiro do Instituto Cultural Italo-Brasileiro, em São Paulo. Representou o Departamento de Direito Internacional da Faculdade de Direito da USP, junto ao Instituto Tecnológico de Aeronáutica, em São José dos Campos.

Acontece, porém, que as atividades de GUSTAVO ZANINI não se restringiram ao magistério, à pesquisa e produção científica tal como delineado acima.

Merecem, ainda, lembrança, a apresentação de tese em dois Congressos sobre Imigração. Refiro-me ao I Congresso İtalo Brasileiro sobre Migraçōes, em agosto de 1985, realizado na Faculdade de Direito, abordando a questão de "Aportamento do Italiano" no Brasil, para a Secção Sócio-Jurídica e cujos Anais vieram a lume em 1987, editado em Roma pelo "Centro Studi Emigrazione", sob o título: "EMIGRAZIONI EUROPEE E POPOLO BRASILIANO”. E, no VI Congresso Brasileiro sobre Imigração e Integração, realizado na Bienal de São Paulo - Ibirapuera, em junho-julho de 1987, também enfocando a questão da migração italiana no Brasil, quando, sob minha coordenação, representávamos, pela primeira vez, a Faculdade de Direito, no evento patrocinado pelo "Jornal do Imigrante" e a Universidade de São Paulo, cujos Anais ainda não foram divulgados.

É melancólico dizer-se, mas não posso deixar de fazê-lo: GUSTAVO ZANINI já estava com a saúde comprometida e, assim mesmo, aceitava as solicitaçōes que lhe eram dirigidas para participar de simpósios, colóquios, diferentes cursos extracurriculares, patrocinados pelo nosso Departamento e pelo Instituto de Direito Internacional e Relações Internacionais.

Perfeitamente engajado no espírito acadêmico destas duas entidàdes, colaborou com palestras ou debates, marcando sua presença nas oportunidades em que tivemos entre nós juristas estrangeiros que vieram trazer as colocações mais recentes sobre determinados assuntos de relevância para o Direito Internacional.

Entretanto, o que mais marcou sua passagem pela Faculdade foram: a lhaneza do trato com todos os que dele se aproximavam; um desejo irrefreável de ministrar aulas, de participar e de colaborar em todas as iniciativas do Departamento de Direito Internacional, como foi agora mesmo ressaltado pelo Profes- 
sor Vicente Marotta Rangel, além do alto espírito cristão no desempenho de seus misteres.

Se, a grande leva de discípulos que teve, admirava-o como lúcido expositor, os colegas do Departamento receberam dele magníficas demonstrações de apoio e de amizade desinteressada.

Com efeito, o Departamento sente, profundamente, o vazio de sua ausência. O Departamento louva o exemplo de coleguismo, reflexo de sua personalidade sempre disposta a substituir qualquer um de nós que, por uma eventual impossibilidade, não pudesse comparecer a alguma aula, de sorte a que nenhum prejuízo houvesse para o corpo discente. do.

Ele soube servir: ao Colega, ao Departamento, à Faculdade como um to-

Por tais motivos, minhas queridas amigas Daisy e Silvinha:

Esta Casa de ensino do Direito, que vive em função dos próprios ideais do Direito, que é a Justiça e que implica em liberdade e democracia, nāo poderia olvidar-se de reverenciar aquele que, no amor ao Direito, foi um justo como professor.

No entanto, se para ambas é difícil o impacto de sua ausência, depois de tanto sofrimento, os ex-alunos, os colegas de ZANINI e a Diretoria da Faculdade de Direito da Universidade de São Paulo, por meu intermédio, se irmanam neste transe.

Ficou-nos: o exemplo de dignidade do professor que honrou o magistério universitário, a lembrança imorredoura de sua estima e de seu entusiasmo, aliados à certeza de que, sua passagem neste mundo, foi a vivência do Sermão das Bem-Aventuranças.

\section{PROFESSOR DALMO DE ABREU DALLARI:}

"Estudantes e antigos alunos de GUSTAVO ZANINI também solicitaram a oportunidade de dar um breve testemunho do valor humano e intelectual do nosso saudoso Mestre. Depois das palavras tão expressivas da Ilustre Professora Georgette Nacarato Nazo concedo a palavra ao estudante André Calestini Montemor que falará pelos alunos

\section{ANDRÉ CALESTINI MONTEMOR:}

Excelentíssimo Senhor Diretor da Faculdade de Direito, Dalmo de Abreu Dallari, Professor Vicente Marotta Rangel, Prezados Professores, Senhoras e Se- 
nhores. Nós, ex-Alunos do Professor GUSTAVO ZANINI, que nos é muito saudoso, temos o desejo de manifestar a nossa homenagem através de um soneto. Ele se chama "A OSTRA":

\author{
"PERDE-SE A VIDA, GANHA-SE A BATALHA". \\ LAPIDAR INSCRIÇÄO DE FRIO JAZIGO \\ POIS CONTÉM UMA IDÉIA QUE PERSIGO: \\ ÂNSIA DE SE FAZER ALGO QUE VALHA. \\ VEJO-A IMPRESSA NUM SEPULCRO ANTIGO \\ DOS TENEBROSOS BOSQUES DA TESSÁLIA \\ QUE MUITO HORROR AOS CRÉDULOS ESPALHA \\ MAS QUE FOI PARA TANTOS BOM ABRIGO. \\ QUANTAS VERDADES O EPITÁFIO ENCERRA! \\ QUAL OSTRA SUBMERGIDA EM MAR DE CRETA \\ QUE PODERÁ TRAZER PÉROLAS BRILHANTES. \\ É A VIDA QUE OS MORTAIS PASSAM NA TERRA \\ E QUE SÓ TEM SENTIDO SE COMPLETA \\ AO SE DEIXAR LEGADO AOS SEMELHANTES. \\ André Calestini Montemor
}

\title{
PROFESSOR DALMO DE ABREU DALLARI:
}

"Em seguida, eu concedo a palavra a um outro estudante que também quis trazer o seu testemunho, o estudante Caramuru Francisco":

\section{CARAMURU AFONSO FRANCISCO:}

"Excelentíssimo Senhor Diretor Professor Dalmo de Abreu Dallari, Excelentíssimo Senhor Chefe do Departamento de Direito Internacional, Professor Vicente Marotta Rangel, Ilustres Professores, Ilustres familiares do saudoso Professor GUSTAVO ZANINI, meus colegas, senhoras e senhores:

"Redundantes seriam as minhas palavras se uma vez mais eu repetisse aqui os talentos do querido mestre GUSTAVO ZANINI; tônica comum em todas as orações aqui pronunciadas foram o Amor, o Carinho e a Dedicação que o saudoso mestre nos imprimiu. Quis o destino que fôssemos a sua última turma e acompanhamos de perto cada passo, a dedicação, o grau da dedicação com que o Professor ZANINI nos acompanhou, como bem disse já seu Mestre, a cada instante lutanto tenazmente. O Professor ZANINI sempre esteve em cada aula, sempre superando obstáculos para nós intransponíveis e somente quando as forças se dissiparam (por total), por completo, o Professor se ausentou das salas de aula. A cada instante, a cada aula ministrada nós sentíamos o amor, a 
dedicação, verdadeira paixão que tinha o Mestre por ensinar seus Pupilos. E, pensávamos nós que a doença, enfim, havia derrotado o nosso querido Mestre. Qual não foi a surpresa, porém, quando poucos dias antes de seu passamento, quando aqui adentrei uma vez mais as Arcadas e o encontrei. Ele me cumprimentou de maneira afável, como sempre, e fez alguns comentários sobre o trabalho que (eu) havia feito, trabalho final do curso do ano passado, trabalho que eu imaginava que ele não teria visto, já que estava muito adoentado, mas qual não foi a surpresa quando então vi que a doença não o tinha vencido. A dedicação, o amor ao ensino continuavam sempre presentes na vida e no espírito do saudoso professor. Por fim, só nos resta constatar que se os homens passam e as instituições permanecem, como a Academia de São Francisco permanece, é porque Ela sempre está embebida das grandes riquezas que homens como GUSTAVO ZANINI deixam perpetuar na sua vida. Muito obrigado"

\section{PROFESSOR DALMO DE ABREU DALLARI:}

"Antes de passar a palavra ao representante da família do nosso querido homenageado, eu quero proceder à leitura de uma carta que me chegou às mãos, nesta manhã. É endereçada pela nossa Eminente Colega Professora Ada Pellegrini Grinover: "Senhor Diretor. Absolutamente impossibilitada de comparecer à cerimônia do dia 3 de março em memória do saudoso colega Professor GUSTAVO ZANINI, de cujo passamento somente agora fui informada, peço encarecidamente a V.Excia., a gentileza de transmitir à excelentíssima esposa e demais familiares, minhas profundas condolências, por tão dolorosa perda, enquanto me associo em espírito às sentidas homenagens que serão prestadas por Vossa Excelência e pelos Professores Vicente Marotta Rangel, Geogette Nacarato Nazo, como pelos estudantes, à família, à figura do inesquecível e querido amigo".

\section{PROFESSOR DALMO DE ABREU DALLARI:}

"Após a manifestação da Professora Aảa Grinover e antes de dar a palavra ao representante da família, eu indago se alguém, eventualmente, queira dizer alguma coisa. A palavra está aberta. Eu tenho a honra de conceder a palavra ao nosso Eminente Colega, dos mais ilustres professores da Universidade, Professor Walter Zanini que falará em nome da familia do nosso querido homenageado. Tem a palavra":

\section{PROFESSOR WALTER ZANINI:}

Eu espero, em rápidas palavras, expressar o reconhecimento da familia a este ato - o reconhecimento de minha cunhada Daisy Flora Ungaretti Zanini, de Sílvia, de irmãos, cunhados e sobrinhos. Acredito que todos nós recebemos com muita emoção esta homenagem a GUSTAVO ZANINI, a que comparecem numerosos professores, alunos e funcionários desta tradicional Academia do Largo de São Francisco. Foi sem dúvida dado um testemunho muito sincero so- 
bre a figura do homem, do professor e do pesquisador GUSTAVO ZANINI. Agradeço as palavras do Professor Dalmo de Abreu Dallari, Diretor desta Faculdade, as palavras do Professor Vicente Marotta Rangel, as palavras da Professora Georgette Nacarato Nazo, as palavras dos estudantes. Foram palavras muito sensíveis que penetraram profundamente em todos nós. Deu-se uma demonstração da trajetória de meu irmão nesta Escola e eu poderia dizer que, no âmbito da comunidade menor, que é a família, uma família de origem imigrante, ele também foi uma figura exemplar, uma figura de permanente estímulo para todos nós, pelos méritos que demonstrou, galgando ao longo dos anos a situação a que chegou nesta Unidade da USP. De sorte que há, na sua composição humana, a necessidade de realçar também esse aspecto que traz, que me permite trazer um complemento ao que foi dito aqui. Uma vez mais, agradeço aos professores e estudantes desta Escola.

\section{PROFESSOR DALMO DE ABREU DALLARI:}

"Embora sentindo grande tristeza, era indispensável que nós rendêssemos essa homenagem ao nosso querido e inesquecível Colega. Foi, na realidade, homenagem singela, feita com a mais absoluta simplicidade, mas uom uma característica muito bem ressaltada pelo nosso querido e eminente Colega Diretor da Escola de Comunicaçōes da Universidade de São Paulo, Doutor Walter Zanini; foi uma homenagem sincera, uma imagem saída do coração, cheia de emoção, cheia de reconhecimento, cheia de tristeza pelo sentimento que ocorreu, na verdade, uma grande perda. Queria apenas concluir, lembrando que GUSTAVO ZANINI à parte de ter sido um Eminente Professor, grande companheiro, funcionário extremamente dedicado à Universidade de São Paulo, foi em toda linha e permanentemente, acentuadamente, um CRISTÃO. O que na verdade não é privilégio do cristianismo inspirar a boa convivência, mas é uma exigência do cristianismo. E GUSTAVO ZANINI foi coerentemente um Cristão e coerente com a sua fé religiosa, soube reconhecer em cada ser humano, um irmão. Soube seguir constantemente o mandamento fundamental do cristianismo que é o mandamento do Amor ao Próximo, vendo em cada ser humano o próximo que deve ser amado. E dentro dessa perspectiva cristã eu posso dizer, também, como cristão, que embora sentindo a perda do querido amigo, embora desde já sentindo a falta do seu companheirismo, eu me rejubilo, pois GUSTAVO ZANINI cresceu espiritualmente e conquistou por sua vida, o seu exemplo, o direito, se se pode falar em direito nesta circunstância, ao repouso eterno, ao repouso que é devido aos que foram justos. GUSTAVO ZANINI foi no sentido cristão da expressão, um homem justo. Com isto, eu quero agradecer a presença de todos os que aqui compareceram para esta singela, mas sincera homenagem ao nosso querido e inesquecível colega e companheiro GUSTAVO ZANINI. Agradeço ao Eminente Professor Vicente Marotta Rangel não só por suas palavras perpassadas de emoção, o seu testemunho humano, tão rico, mas também pela feliz iniciativa de ter sugerido esta homenagem. Agradeço, também, a Eminente Professora Georgette Nacarato Nazo, por suas palavras tão expressi- 
vas, por seu testemunho tão preciso, tão oportuno, que nos permitiu rememorar a trajetória do Eminente Professor e querido colega, como também, nos permitiu rememorar o comportamento do homem GUSTAVO ZANINI. Agradeço, também, a presença do Eminente Professor Emérito da Universidade de São Paulo, Goffredo da Silva Telles, a presença dos mais ilustres Professores desta Faculdade que aqui compareceram, como agradeço, também, a presença dos alunos. E quero ressaltar a presença dos funcionários que aqui estão, sobretudo funcionários do Departamento de Direito Internacional, funcionários da Revista e da Biblioteca da Faculdade, que mantiveram convivência muito estreita com GUSTAVO ZANINI. A presença destes funcionários é um testemunho altamente expressivo, porque são pessoas que tiveram a felicidade da convivência diária e quiseram estar aqui para render a sua homenagem, para com sua presença darem também o seu testemunho. Agradeço, também, a presença dos estudantes, altamente expressiva. Tantas vezes já se disse que a juventude é generosa, mas às vezes é impiedosa. Impiedosa na sua espontaneidade, na sua sinceridade. Isso significa que quando o jovem homenageia alguém é porque esse alguém é muito merecedor da homenagem. $\mathrm{E}$ os jovens vieram homenageá-lo. $\mathrm{E}$ agradeço, finalmente, não só o nosso Eminente e querido colega doutor Walter Zanini, como a todos os familiares, que aqui compareceram e que nos deram esta oportunidade de manifestar publicamente nosso apreço, nosso reconhecimento, nossa gratidão a GUSTAVO ZANINI, que enriqueceu, de maneira marcante, a História desta Faculdade. Está encerrada a Sessão".

\section{8 - TURMA “GUSTAVO ZANINI”}

Complementando a homenagem e para perpetuar a memória do Professor GUSTAVO ZANINI, os Bacharelandos da Faculdade de Direito do Largo de São Francisco, numa demonstração de carinho e respeito ao professor, deram o nome de GUSTAVO ZANINI à Turma de 1988.

Na solenidade de Colação de Grau, o Formando José D’Amico Bauab, assim se expressou: “... A esta altura consistiria um lapso imperdoável deixar de homenagear, em particular, o saudoso Professor GUSTAVO ZANINI, nome de batismo da Turma. Ele não nos deu apenas lições de Direito Internacional Público, deu-nos, também, lições de vida" 